\title{
Effect of Potassium Alum Salt Particles on the Activation Energy of Poly(ethylene oxide) Doped with Conductive Carbon Black (CB) Nanoparticles
}

\author{
ABEER ADAILEH ${ }^{*}$, MOHAMMED AL-TWEISSI ${ }^{2 *}$, HUSAM MIQDAD ${ }^{1}$ \\ ${ }^{1}$ Applied Science Private University, Faculty of Arts and Science, Department of Basic Science, Amman, Jordan \\ ${ }^{2}$ Al-Hussein Bin Talal University, College of Science, Physics Department, Ma'an, Jordan
}

\begin{abstract}
The electrical properties of conductive carbon black (CB) nanoparticles (0.1wt percent) doped thin films made of poly(ethylene oxide) (PEO) filled with varying amounts of the electrolyte potassium alum salt and doped with conductive carbon black (CB) nanoparticles (0.1wt percent) have been investigated. The dependence of the activation energy of the composites on frequency, temperature, and filler content was studied using the AC impedance technique. The current research looked at how activation energy changed with frequency $(200-1000 \mathrm{kHz})$ and temperature $\left(30-55^{\circ} \mathrm{C}\right)$ for composites with varied potassium alum salt concentrations: $0,2,4,8,12$, and $16 \mathrm{wt}$. percent. The activation energy (Ea) values measured exhibited frequency, temperature, and filler content relationships. According to polarization processes, the activation energy of the produced sheets decreases with the potassium alum salt content in the composite and decreases with the temperature. With increasing frequency, the activation energy of the produced thin films decreases.
\end{abstract}

Keyword: poly(ethylene oxide)(PEO), CB, potassium alum, activation energy, frequency, temperature

\section{Introduction}

Plastics, whose molecules are made up of long groups of carbon and hydrogen atoms, have few or no free electrons. Therefore, most of them are bad conductors of electricity. So that scientist focused on enhancing their electrical conductivity and improving their properties. Polymers can be n-type (that is, the dominant free electron) or p-type (that is, the dominating hole), just like semiconductors. Polymers display a variety of electrical properties that reflect their molecular structures and kinetics. By adding appropriate impurities, the electrical characteristics can be tailored to meet specific needs [1].

Polymer compounds are materials in which a second component with very distinct properties is combined with the polymer to improve the product's attributes. The second component reinforces the product by enhancing its hardness or strength [2]. Composite materials have evolved into standard technological materials that are designed and produced for a wide range of uses. Composites seem to be the preferred material for a wide range of engineering and science applications today. They are distinguished by their ease of fabrication, low cost, and excellent strength. It's usually applied to a matrix to help it enhance or change its qualities. The reinforcement disperses uniformly throughout the matrix in a discontinuous phase [3].

When a filler/polymer matrix composition is used instead of a pure polymer electrolyte, it can improve ionic conductivity and interfacial contact [4].

Poly(ethylene oxide) (PEO) is a crystalline thermoplastic polymer that is widely used in industrialized countries due to its favorable properties: it is a neutral, non-toxic, and water-soluble polymer with a low cost. Polyethylene oxide (PEO) is represented by the formula $\left(-\mathrm{CH}_{2} \mathrm{CH}_{2} \mathrm{O}-\right) \mathrm{n}$, where $\mathrm{n}$ is the number of oxygen-ethylene groups in the main polymer chain. Figure 1 shows the chemical structure of the repeating unit of ethylene oxide.

*email: abeerdiab@ymail.com 


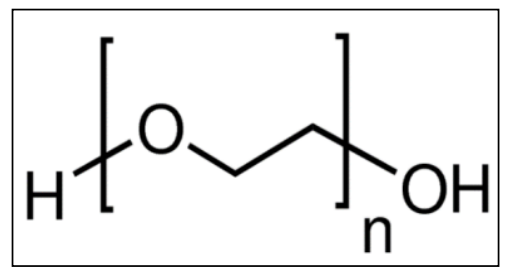

Figure 1. Structure of

poly(ethylene oxide)

Poly(ethylene oxide) (PEO) polymers are soluble in water as well as in many organic solvents (for example, methylene chloride, toluene, ethanol, chloroform, and acetone). PEOs are white solids having melting points based on their molecular weights. The interesting properties of PEO are its relatively low melting point $65^{\circ} \mathrm{C}$, low toxicity, and low glass transition temperatures of $-65^{\circ} \mathrm{C}$, which allows ion transport at ambient temperature. On the other hand, PEO is the best used polymer, due to its large solvating power with ions, good processing ability, and outstanding mechanical properties [1,5].

The chemical formula of potassium alum is $\mathrm{KAl}\left(\mathrm{SO}_{4}\right)_{2}$. Also, it is available in another dodecahydrate form as $\mathrm{KAl}\left(\mathrm{SO}_{4}\right)_{2} .12\left(\mathrm{H}_{2} \mathrm{O}\right)$. When the sulfate of a singly charged cation (e.g., $\left.\mathrm{K}^{+}\right)$is combined with the sulfate of any of a number of triply charged cations (e.g., $\mathrm{Al}^{3+}$ ), a variety of hydrated double salts are formed. With sulfate, single-charged potassium cations, and other elements and compounds, aluminum sulfate can create alum. It is commonly used in leather tanning, dyeing, water purification, fire retardant textiles, and baking powder. Because this molecule is a salt, it dissolves fully into individual ions in a solution. In contrast to coordination compounds that keep the same coordination geometry in the solid and solution stages, the octahedral coordination of metal ions is dependent on the crystal structure in this case [6].

Carbon black (CB) is a form of para-crystalline carbon. It's a conductive material comprised largely of carbon atoms or aggregates, although it can also have large amounts of hydrogen and oxygen. It's used as a reinforcing filler in polymers to improve electrical conduction and reduce resistance. This property is thought to be a result of the carbon black particle structure joining them together to form conductive channels or due to the "tunnel effect" of electrons hopping between dispersed carbon black particles $[7,8]$.

\section{Materials and methods}

\subsection{Materials and composites films preparation}

PEO, alum and carbon black powders were combined together with methanol as a solvent. The mixture was then stirred for two days with a rotating magnet to achieve a homogenous mixture. The combination was directly casted to tiny films in a glass mold. The methanol was allowed to evaporate fully at room temperature after two days. For two days, all samples were dried in a $40^{\circ} \mathrm{C}$ oven.

\subsection{Electrical measurements}

Impedance $(Z)$ and phase shift angle ( $\varphi$ in degrees) measurements with an LF impedance analyzer were used to investigate the alternating current electrical properties of polyethylene oxide/alum thin films doped with carbon black. Impedance measurements were performed at different temperatures and applied field frequency range from $30 \mathrm{kHz}$ to $3 \mathrm{MHz}$. In the sample holder shown in Figure 2, the test specimens were firmly inserted between two copper electrodes. The impedance analyzer was connected to these electrodes via cables. Disc-shaped samples with a diameter of $2 \mathrm{~cm}$ and a thickness of $120 \mu \mathrm{m}$ were cut from the prepared films. The test samples were packed firmly in a compartment between two copper electrodes connected to the impedance analyzer by cables. The temperature of the cell was measured using thermocouple wires after it was placed in an oven. To achieve a constant condition of temperature, a 20 min interval was maintained between subsequent impedance measurements. To achieve a constant condition of temperature, a 20 min interval was maintained between subsequent impedance measurements. By altering the applied frequency, the impedance analyzer reads the sample's impedance and phase angle data. The mean and standard deviations were estimated with a mean error of around (3-5\%). Impedance measurements were taken in $5^{\circ} \mathrm{C}$ steps throughout a temperature range of 
$\left(30^{\circ} \mathrm{C}-55^{\circ} \mathrm{C}\right)$ in a frequency range of about $(200-1000 \mathrm{kHz})$. No higher temperature measurements were taken since the melting point of poly(ethylene oxide) is around $60^{\circ} \mathrm{C}$. At steady state, temperature data was taken.

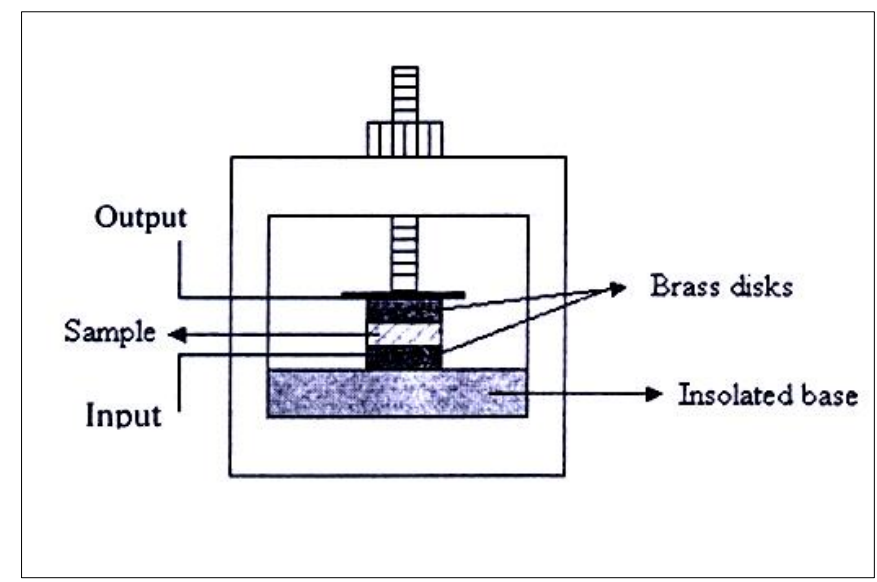

Figure 2. The sample holder diagram impedance analyzer

Dielectrics are a particular class of materials that are insulators under almost all situations. Under the influence of an external electric field, their ions, electrons, or molecules can be polarized. which is an interesting and important characteristic. The total capacitance of these devices will rise when these materials are inserted between the charged plates, as in capacitors. This use is one of the material's most important applications $[9,10]$.

The following equations can be used to determine the real and imaginary components of the sample's complex impedance:

$$
\begin{aligned}
Z^{\prime} & =Z \cos \varphi \\
Z^{\prime \prime} & =Z \sin \varphi
\end{aligned}
$$

The sample's dielectric constant $\mathcal{E}^{\prime}$, and dielectric loss $\mathcal{E}^{\prime \prime}$ are computed using the following formulae [9]:

$$
\begin{gathered}
\varepsilon^{\prime}=\frac{z^{\prime \prime}}{2 \pi f C^{\circ} Z^{2}} \\
\varepsilon^{\prime \prime}=\frac{z^{\prime}}{2 \pi f C^{\circ} Z^{2}}
\end{gathered}
$$

where $f$ is the frequency of the electric fields that generated from alternating current, and Co is the capacitance of the two plates of the cell (capacitor) when the region between them has air and is given by:

$$
\mathrm{C}_{\mathrm{o}}=\varepsilon_{\mathrm{o}} \mathrm{A} / \mathrm{d}
$$

where $\mathrm{A}$ is the area of the plates, $\mathrm{d}$ is the distance between the two plates, and $\varepsilon_{\mathrm{o}}$ is the electrical permittivity of free space $\left\{\varepsilon_{o}=8.854 \times 10^{-12} \mathrm{~F} \cdot \mathrm{m}^{-1}\right\}$.

The sample's AC conductivity was determined using the following equation [11]:

$$
\sigma_{\mathrm{AC}}=2 \pi \mathrm{f} \varepsilon_{\mathrm{o}} \varepsilon^{\prime \prime}
$$


The Arrhenius equation is used to compute the activation energy $\left(\mathrm{E}_{\mathrm{a}}\right)$ of the conduction process, which is provided by:

$$
\sigma=\sigma_{\mathrm{o}} \exp \left[-\mathrm{E}_{\mathrm{a}} / \mathrm{k}_{\mathrm{B}} \mathrm{T}\right]
$$

where $\sigma$ is the conductivity, $\sigma_{\mathrm{o}}$ is the material constant conductivity, $\mathrm{T}$ is the temperature of the material in Kelvin, and $\mathrm{k}_{\mathrm{B}}$ is the Boltzmann constant $\left(\mathrm{k}_{\mathrm{B}}=1.38 \times 10^{-23} \mathrm{~J} / \mathrm{K}\right)$ [12].

\section{Results and discussions}

The electrical properties of polyethylene oxide/alum composites doped with carbon black, containing $0,2,4,8,12$ and $16 \%$ by weight potassium alum salt were studied, and some of their physical parameters such as the AC electrical conductivity and activation energy were determined. Potassium alum salt added to the matrix of polyethylene oxide to compose thin films, is being investigated to evaluate the role of the potassium alum salt particles in the process of activation energy when the electric field is affected. Understanding the type and form of charge transmission in conducting materials is the goal of investigating activation energy in polymers [13].

\subsection{Activation energy determination}

The minimum thermal energy required to activate ions, atoms and molecules for conduction at which they can undergo physical transfer is known as activation energy (Ea). Activation energy values were determined from the straight-line slopes obtained by plotting the natural logarithm of conductance ( $\mathrm{Ln}$ $\left.\sigma_{\mathrm{AC}}\right)$ versus $(1000 / \mathrm{T})$ for all thin films at frequencies $(200,400,600,800,1000 \mathrm{kHz})$ as shown in Figures (3-8).

The activation energy values were determined using the Arrhenius Equation (7) and summarized in Table 1, which shows the relationship between activation energy and frequency for thermally activated conduction processes (ionic and electronic). It was observed that with increasing the frequency, the activation energy decreases for all tested composites. The decrease in activation energy reflects electronic mobility, higher ionic and increasing in electrical conduction in the sample's membranes [11].

Table 1. The activation energy values for composites

\begin{tabular}{|c|c|c|c|c|c|c|}
\hline \multirow{3}{*}{$\begin{array}{l}\text { Frequency } \\
\quad(\mathbf{k H z})\end{array}$} & \multicolumn{6}{|c|}{ Composite's content } \\
\hline & neat PEO & $2 \mathrm{wt} . \%$ alum & 4wt.\% alum & 8wt.\% alum & 12wt.\%alum & 16wt.\%alum \\
\hline & $\begin{array}{c}\mathrm{E}_{\mathrm{a}} \\
(\mathrm{eV})\end{array}$ & $\begin{array}{c}\mathrm{E}_{\mathrm{a}} \\
(\mathrm{eV})\end{array}$ & $\begin{array}{c}\mathrm{E}_{\mathrm{a}} \\
(\mathrm{eV})\end{array}$ & $\begin{array}{c}\mathrm{E}_{\mathrm{a}} \\
(\mathrm{eV})\end{array}$ & $\begin{array}{c}\mathrm{E}_{\mathrm{a}} \\
(\mathrm{eV})\end{array}$ & $\begin{array}{c}\mathrm{E}_{\mathrm{a}} \\
(\mathrm{eV})\end{array}$ \\
\hline 200 & 0.324 & 0.309 & 0.276 & 0.260 & 0.247 & 0.218 \\
\hline 400 & 0.316 & 0.291 & 0.256 & 0.244 & 0.235 & 0.203 \\
\hline 600 & 0.307 & 0.283 & 0.246 & 0.232 & 0.232 & 0.187 \\
\hline 800 & 0.258 & 0.247 & 0.230 & 0.213 & 0.211 & 0.182 \\
\hline 1000 & 0.232 & 0.236 & 0.219 & 0.204 & 0.197 & 0.155 \\
\hline
\end{tabular}




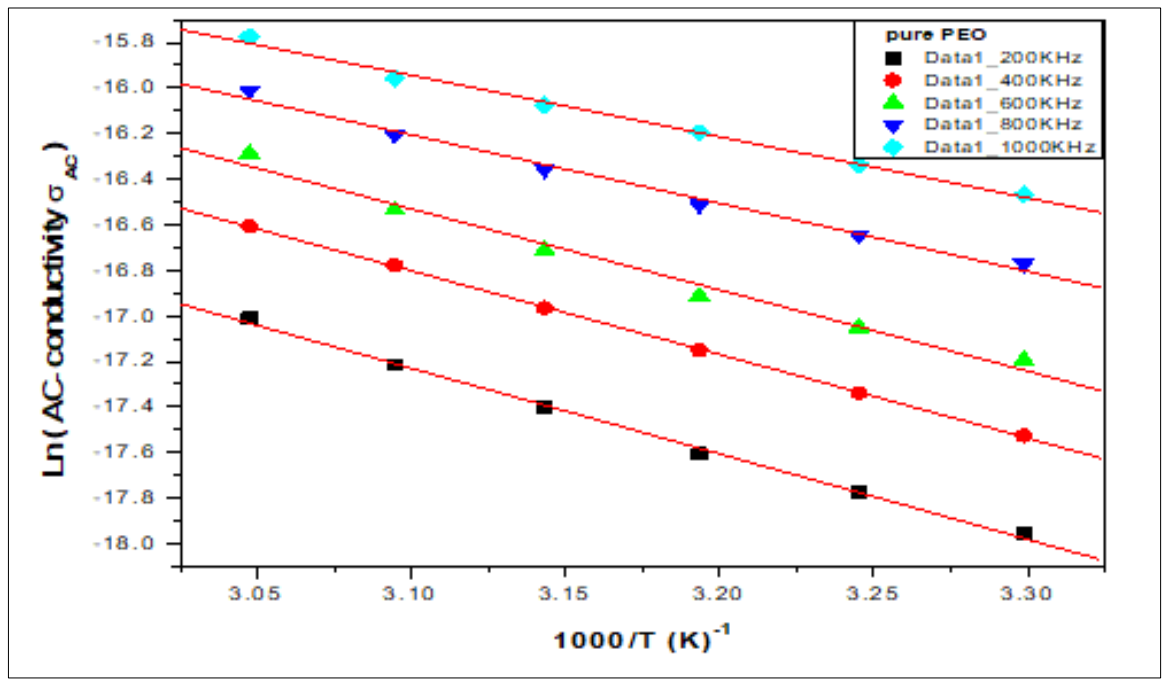

Figure 3. $\operatorname{Ln}\left(\sigma_{\mathrm{AC}}\right)$ versus $(1000 / \mathrm{T})$ for neat PEO

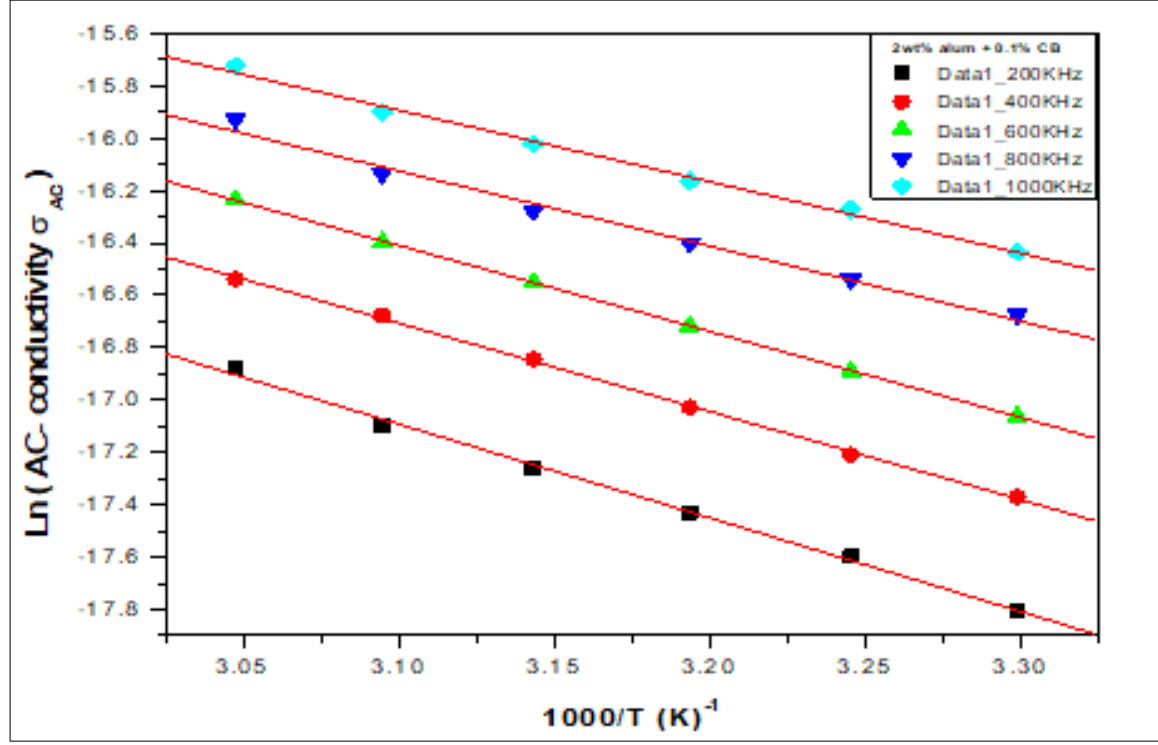

Figure 4. $\operatorname{Ln}\left(\sigma_{\mathrm{AC}}\right)$ versus $(1000 / \mathrm{T})$ for $2 \mathrm{wt}$. \%alum

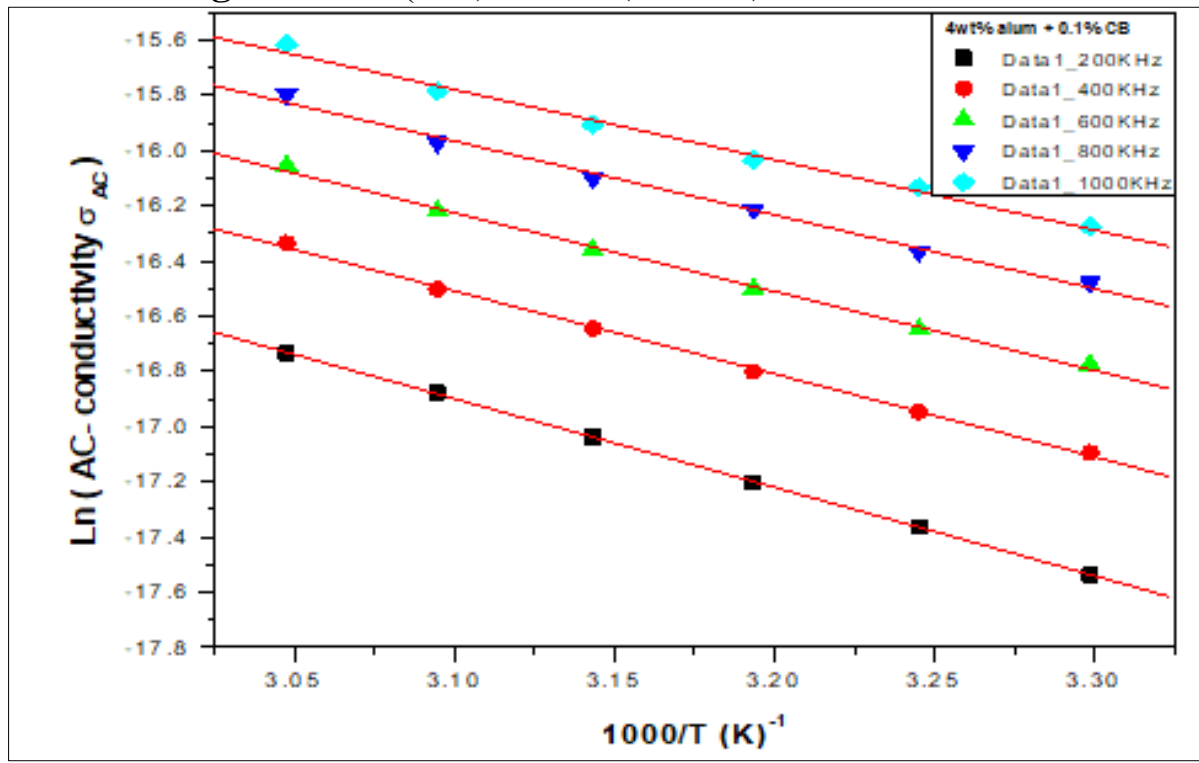

Figure 5. $\operatorname{Ln}\left(\sigma_{\mathrm{AC}}\right)$ versus $(1000 / \mathrm{T})$ for $4 \mathrm{wt} . \%$ alum 


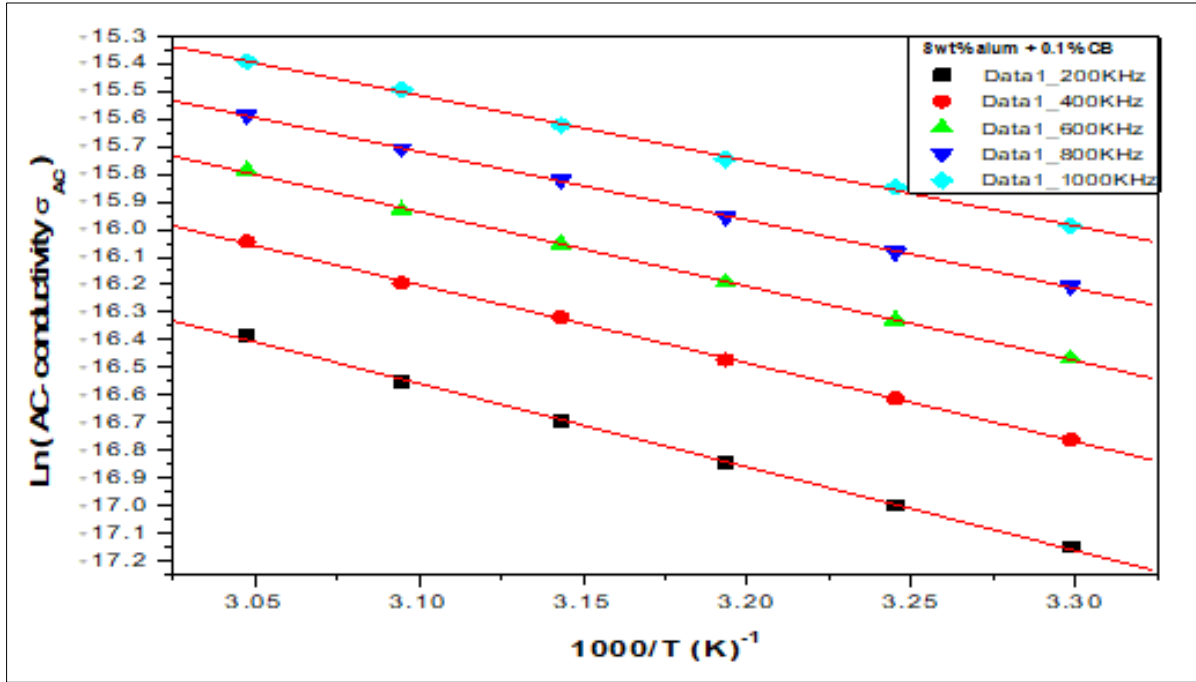

Figure 6. $\operatorname{Ln}\left(\sigma_{\mathrm{AC}}\right)$ versus $(1000 / \mathrm{T})$ for $8 \mathrm{wt}$. \% alum

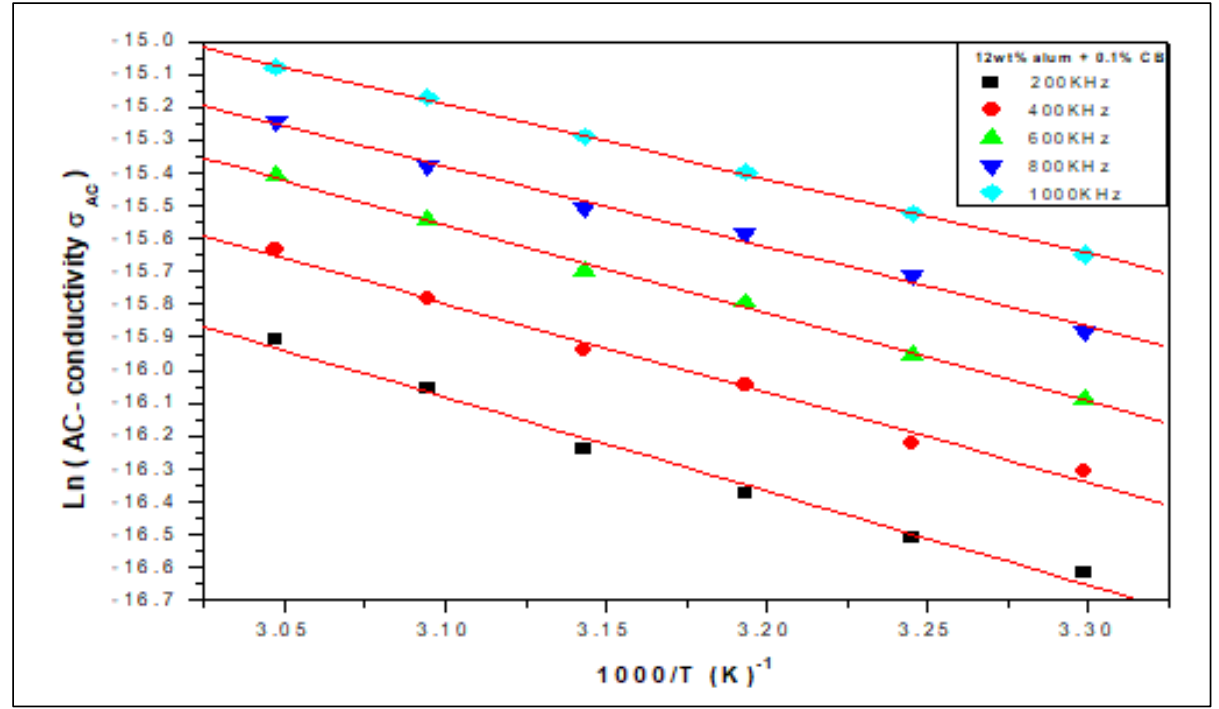

Figure 7. $\operatorname{Ln}\left(\sigma_{\mathrm{AC}}\right)$ versus $(1000 / \mathrm{T})$ for $12 \mathrm{wt} . \%$ alum

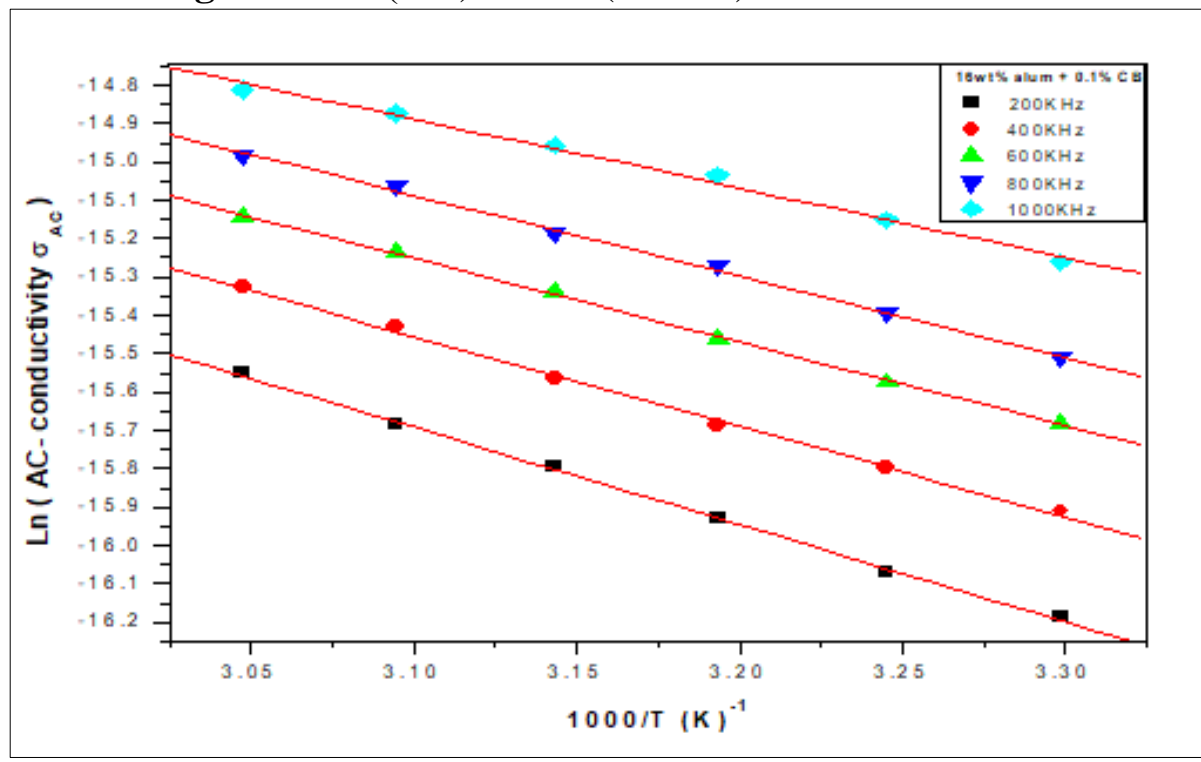

Figure 8. $\operatorname{Ln}\left(\sigma_{\mathrm{AC}}\right)$ versus $(1000 / \mathrm{T})$ for $16 \mathrm{wt}$. \% alum 
Table 2 contains the activation energy values for several composites at $600 \mathrm{kHz}$, which are drawn against the concentration in Figure 9 to investigate the effect of the alum concentration in the composites on the activation energy values. Figures 9 and 10 show that the highest conductivity value and the lowest activation energy values were observed in the $16 \mathrm{wt} . \%$ polyethylene oxide/alum sample (which has the largest potassium alum concentration), where the lowest $\sigma_{\mathrm{AC}}$ value and the highest activation energy were those of the neat polyethylene oxide sample. This noticed decrease in activation energy value means that the polyethylene oxide/ alum thin films energy will be narrower, referring to the production of localized energy states by heating, which increases the ability of the electron to tunnel or jump from the valence to conduction energy band and increases ion mobility, these occurrences increase the amorphous region in the polymer PEO and cause more active segmental motion, which activates the electron hopping process and so increases conductivity. The sudden decrease of activation energy from $12 \mathrm{wt} . \%$ to $16 \mathrm{wt} . \%$ is due to the presence of large amounts of $\mathrm{K}^{+}$and $\mathrm{Al}^{+3}$ ion in the composite, which improve the ionic conduction process.

Figure 11 shows that with increasing the frequency the $\left(\mathrm{E}_{\mathrm{a}}\right)$ decreases because at higher field, more charges and ions are moved, causing more participation of activated ions conduction. It can be seen that $\left(E_{a}\right)$ decreases at higher frequency and higher alum content.

Figure 12 shows that as the temperature rises, the values of AC-conductivity increase, implying that the values of activation energy decrease. The mobility at the localized sites bridged by the molecules of alum in the amorphous areas present in the polymer electrolyte could be controlling the observed rise in conductivity and decrease in (Ea) values with increasing temperature or alum content. The movement of carbon black particles attempting to build a percolation network can be accelerated by increasing temperature. Carbon black Particles may form in the matrix due to the (PEO) matrix's appropriate mobility at high temperatures, improving the sample's conductivity. The amorphous form of the polymer simplifies the quick $\mathrm{K}^{+}$and $\mathrm{Al}^{+3}$ ion motions in the polymer complex, resulting in a low (Ea) for $\mathrm{Al}^{+3}$ and $\mathrm{K}^{+}$ions in the alum transition. The ions $\mathrm{Al}^{+3}$ and $\mathrm{K}^{+}$are involved in the ionic conduction process.

This observed behavior of alum composites seems to correlate with the $\mathrm{E}_{\mathrm{opt}}$ and $\mathrm{AC}$ conductivity behavior. Low activation energies indicate the presence of localized energy levels in the forbidden energy gap in the investigated composites that function as semiconducting materials $[15,16]$.

At temperatures above $45^{\circ} \mathrm{C}$, the (PEO) matrix has sufficient mobility, thus carbon black Particles, $\mathrm{K}^{+}$and $\mathrm{Al}^{+3}$ ions could take place in the matrix which makes the conductivity increases suddenly in the samples with higher concentration of alum.

Table 2. The activation energy values for composites at $600 \mathrm{kHz}$

\begin{tabular}{|c||c|}
\hline Samples & $\begin{array}{c}\text { Activation Energy } \\
\mathrm{E}_{\mathrm{a}}(\mathrm{eV})\end{array}$ \\
\hline \hline neat PEO & $0.3073 \pm 0.0077$ \\
\hline 2 wt.\% & $0.2834 \pm 0.0071$ \\
\hline 4 wt.\% & $0.2461 \pm 0.0062$ \\
\hline 8 wt.\% & $0.2322 \pm 0.0058$ \\
\hline 12 wt.\% & $0.2320 \pm 0.0085$ \\
\hline 16 wt. $\%$ & $0.1871 \pm 0.0047$ \\
\hline
\end{tabular}




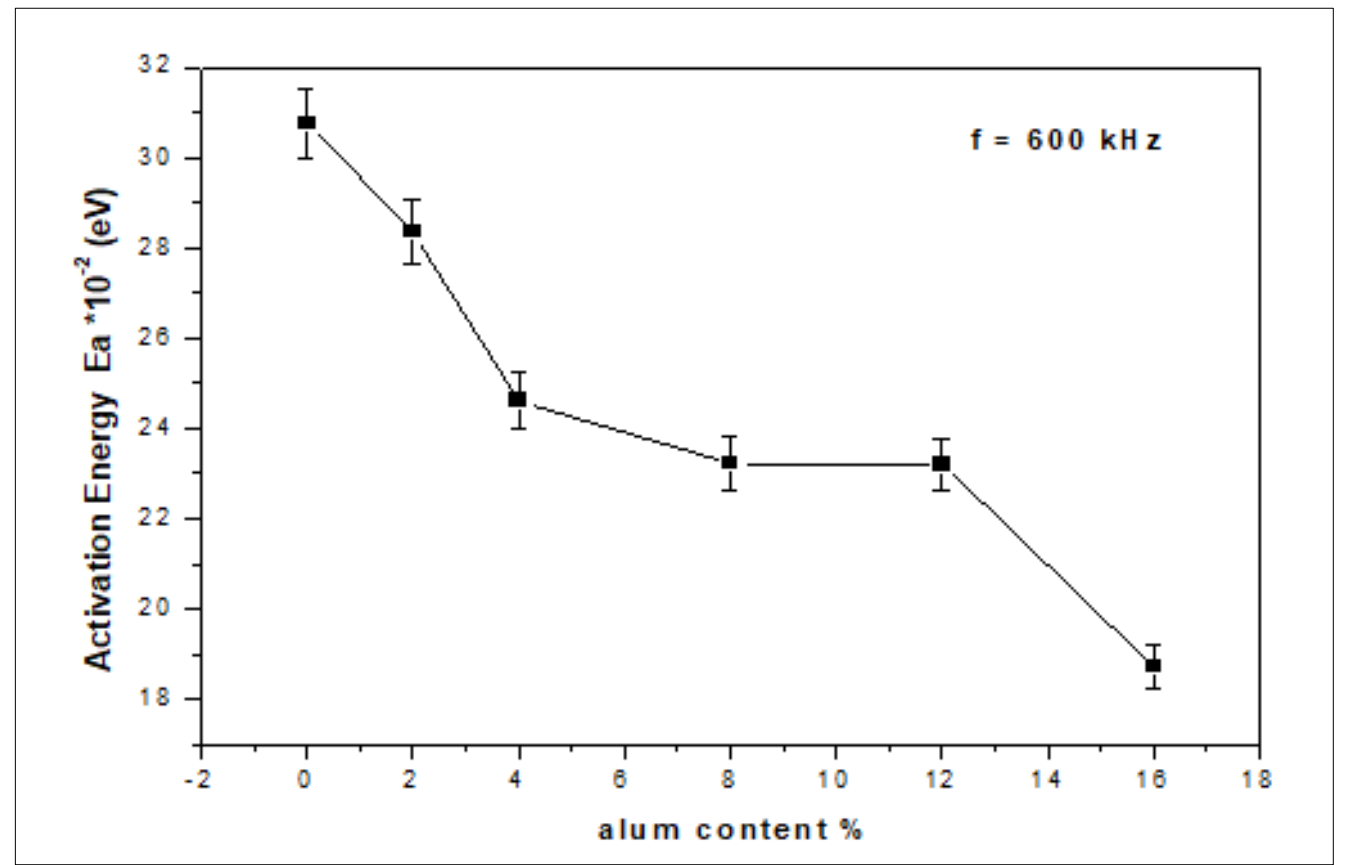

Figure 9. Variation of activation energy $\left(\mathrm{E}_{\mathrm{a}}\right)$ values with alum content at $600 \mathrm{kHz}$

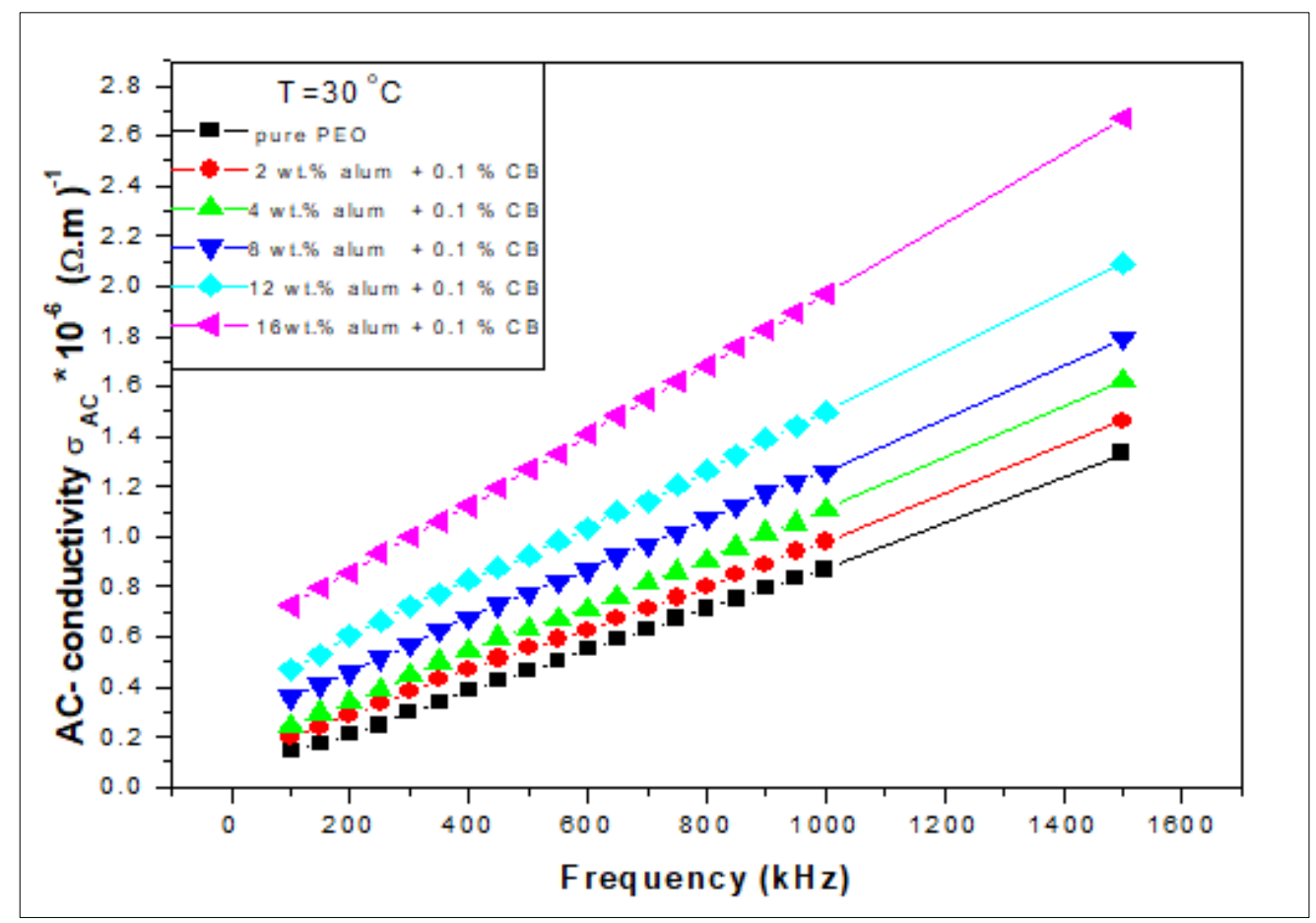

Figure 10. Variation of AC conductivity with frequency 


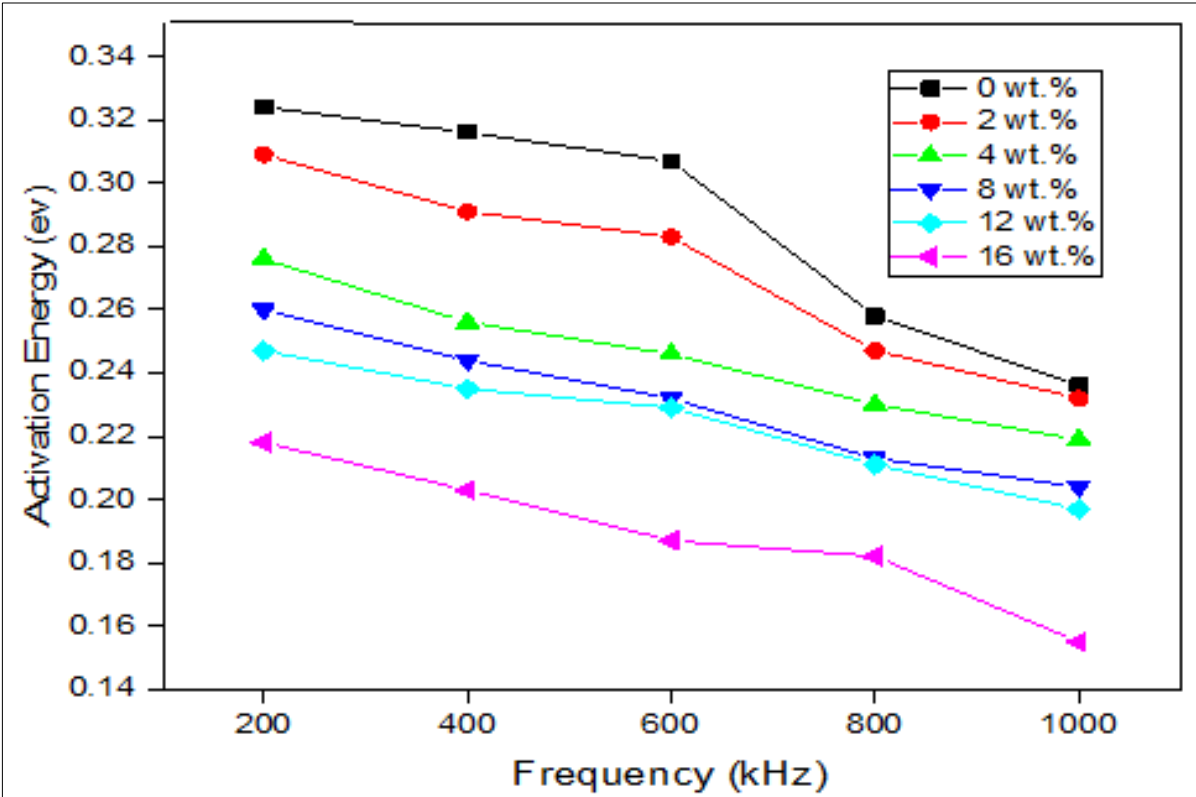

Figure 11. Variation of activation energy (Ea) with frequency at $\mathrm{T}=30^{\circ} \mathrm{C}$

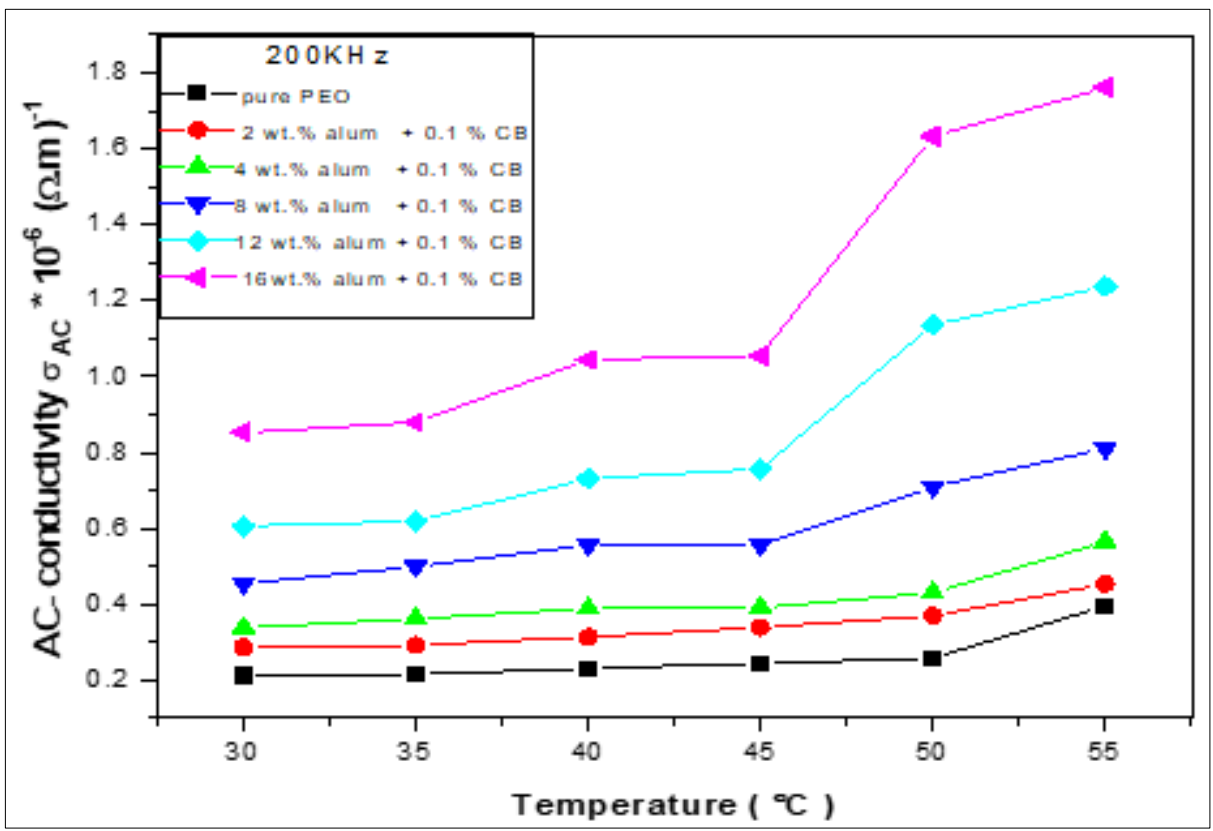

Figure 12. AC-conductivity $\left(\sigma_{\mathrm{AC}}\right)$ versus temperature for $\mathrm{PEO}$ / alum composites

\section{Conclusions}

The activation energy of poly (ethylene oxide) (PEO) packed with varied amounts of electrolyte potassium alum salt and doped with conductive carbon black (CB) nanoparticles $(0.1 \mathrm{wt} \%)$ was investigated. We deduced the following from the results:

-The activation energy decreases with an increase in the potassium alum concentration.

-The activation energy is decreased with increasing temperature.

-The activation energy is decreased at a higher frequency.

\section{References}

1.WILLIAM, D., CALLISTER, Jr., Materials Science and Engineering. An Introduction $9^{\text {th }}$ edition. New York: John Wiley and sons, 2014. 
2.BOWER, DAVID I., An introduction to Polymer Physics, London: Cambridge University press, 2002. 3.KILLOPS, V., Introduction to Organic Geochemistry, (2nd.). Blackwell Science Ltd. US, 2005.

4.MALLICK, P.K., CONSTITUENTS IN: Composites Engineering Handbook (Materials Engineering, ISBN: 1997, 978-0824793043 CRC Press, USA.

5.NEUGEBAUER, D., Graft Gopolymers with Goly(ethylene oxide) Segments. Polymer International, 2007, 56, 1469-1498.

6.KUMARI, L., PRASAD. V., SUBRAMANYAM. S. V., Effect of iodine incorporation on the electrical properties of amorphous conducting carbon films. Journal of Carbon, 2006, 41(9), 1841-1846 7.RAYNOR-CANHAM, G.; OVERTON, T., Descriptive Inorganic Chemistry, 6thEd. W.H. Freeman and Co., New York City, 2014, NY, USA, pp 113-116, 530-536.

8.OU, R. GERHARDT. R. A., MARRETT, C, MOULART, A., COLTON. J. S., Assessment of percolation and homogeneity in ABS/carbon black composites by electrical measurements. Journal of Composites: 2003, Part B, 34:607-614.

9.POLLOCK, D., Physical Properties of Materials for Engineers. 1993, (2nd ed.) CRC Press, Inc.

10.MIQDAD, H., The Effects of (CB) Nanoparticles Additive on Dielectric and AC Electrical Conductivity of (PEO) Thin Film. ARPN Journal of Engineering and Applied Sciences, 2019, VOL. 14, NO. 22, 3865-3876.

11.HUMMEL, R.E., Electronic Properties of Materials, (2nd ed.). Springer-Verlag, NewYork.1993.

12 MIQDAD, H., ADAILEH, A., Characterization of the Electric Properties of PEO/Alum Composite Dopant with Carbon Black Nanoparticles at $\mathrm{t}=40^{\circ} \mathrm{C}$, Journal of Engineering and Applied Sciences, 2020, vol. 15 , no. $9,1036-1048$

13AGRAWAL, R. C., PANDEY, G. P., Solid polymer electrolytes: materials designing and all-solidstate battery applications: an overview, Journal of Application Physics, 2008, 41 - 223001 (18pp).

14.BHARGAV, P., MOHAN, V., SHARMA, A., RAO, V., Structural, Electrical and optical characterization of PVA Polymer electrolyte films, International Journal of polymer Materials, 2007, 56: 579 .

15.AL-TWEISSI, M., TARAWNEH, M. A., OWAIDAT, M. Q., ALSBOUL, M., Optical characterization of thin films poly(ethylene oxide) doped with cesium iodide, Journal of nano- and electric physics, 2018, 10(5):05016.

16.AL- TWEISSI, M., AYISH I.O., AL-RAMADIN Y., Electrothermal and Optical Properties of Hybrid Polymer Composites. Journal of nano- and electric physics, 2018, 10(2):02006.

$\overline{\text { Manuscript received: } 24.05 .2021}$ 